\title{
PROPULSION OPTIONS FOR THE GLOBAL PRECIPITATION MEASUREMENT CORE SATELLITE
}

\author{
Eric H. Cardiff*, Gary T. Davis ${ }^{\dagger}$, and David C. Folta ${ }^{\ddagger}$ \\ NASA Goddard Space Flight Center \\ Greenbelt, MD 20771
}

\begin{abstract}
$\underline{\text { Abstract }}$
This study was conducted to evaluate several propulsion system options for the Global Precipitation Measurement (GPM) core satellite. Orbital simulations showed clear benefits for the scientific data to be obtained at a constant orbital altitude rather than with a decay/reboost approach. An orbital analysis estimated the drag force on the satellite will be 1 to $12 \mathrm{mN}$ during the five-year mission. Four electric propulsion systems were identified that are able to compensate for these drag forces and maintain a circular orbit. The four systems were the UK-10/T5 and the NASA $8 \mathrm{~cm}$ ion engines, and the ESA RMT and RIT10 EVO radio-frequency ion engines. The mass, cost, and power requirements were examined for these four systems. The systems were also evaluated for the transfer time from the initial orbit of 400 $x 650 \mathrm{~km}$ altitude orbit to a circular $400 \mathrm{~km}$ orbit. The transfer times were excessive, and as a consequence a "dual" system concept (with a hydrazine monopropellant system for the orbit transfer and electric propulsion for drag compensation) was examined. Clear mass benefits were obtained with the "dual" system, but cost remains an issue because of the larger power system required for the electric propulsion system. An electrodynamic tether was also evaluated in this trade study.
\end{abstract}

\section{Introduction}

The Global Precipitation Measurement (GPM) mission will be launched in late 2008 to measure the amount and type of precipitation around the globe. Measurements will be performed by a core spacecraft and several smaller "constellation" satellites. The core satellite is being designed and built by NASA's Goddard Space Flight Center. The design of the propulsion system for the core satellite is discussed in this paper. The $3000 \mathrm{~kg}$ core satellite will be launched on a H-IIA rocket from the Tanegashima Space Complex into an initial $400 \times 650 \mathrm{~km}$ orbit. The onboard propulsion system will transfer the satellite to the operational $400 \mathrm{~km}$ circular orbit at $65^{\circ}$ inclination. The core satellite will study the quantity of rainfall and the three-dimensional structure of clouds and precipitation. The measurements will be made with a passive microwave radiometer and a dual frequency active radar.

\footnotetext{
* Propulsion Engineer, Member, AIAA

† Senior Propulsion Engineer, Member, AIAA

$\ddagger$ Senior Aerospace Engineer, Member, AIAA
}

The propulsion system is required to perform two primary functions. The first is to transfer the satellite from the launch insertion orbit to the final circular orbit. The second function is to maintain the $400 \mathrm{~km}$ altitude by compensating for atmospheric drag.

A trade study was performed to determine the optimum propulsion system design for the core spacecraft. The baseline hydrazine system has the advantage of simplicity and cost, but requires much more propellant mass and more frequent reboosting. An electric propulsion (EP) system would require more power and cost more, but would significantly reduce the total mass and also improve the rate of coverage by the science measurements.

Electric Propulsion System Benefit to Instrument Performance

The ability of an EP system to maintain the 400 $\mathrm{km}$ orbit within very small tolerances has a significant effect on the performance of the instruments. The chemical propulsion system is 
only required to maintain an altitude variation of $\pm 5 \mathrm{~km}$. Although there is very little difference between the resolution of the instruments at 405 $\mathrm{km}$ and the resolution of the instruments at 400 $\mathrm{km}$, the altitude has a large effect on the coverage. Specifically, the amount of time required to image the entire viewable area (a band between $\pm 65^{\circ}$ latitude), and hence the amount of time between observations of the same location, is much higher at lower altitudes. These times are different for each of the instruments because of the different footprints for each instrument, but the trends for all of the instruments are similar.

One of the goals of the mission is to maximize the rate of coverage by the instruments. Previous work by Mailhe et al. examined the ideal altitude for the spacecraft, but the authors only considered a constant altitude. ${ }^{1}$ However, the rates of coverage from a constant altitude orbit are significantly different from the rates of coverage from a decaying orbit. Orbital simulations were conducted to examine the effects of both a decaying and a constant orbital altitude on the coverage of the radiometer instrument. In one simulation, the satellite decays from an initial orbit at $405 \mathrm{~km}$ to an altitude of $395 \mathrm{~km}$ over the course of 11 days. The satellite covers a band of $\pm 65^{\circ}$ latitude approximately 8 times in one cycle, as shown in Figure 1. The results of an orbital simulation with the satellite maintaining a constant orbital altitude of $400 \mathrm{~km}$ over the same period of time is shown in Figure 2. The $\pm 65^{\circ}$ latitude band is covered approximately 10 times. This is $25 \%$ more often than with a decaying orbit.

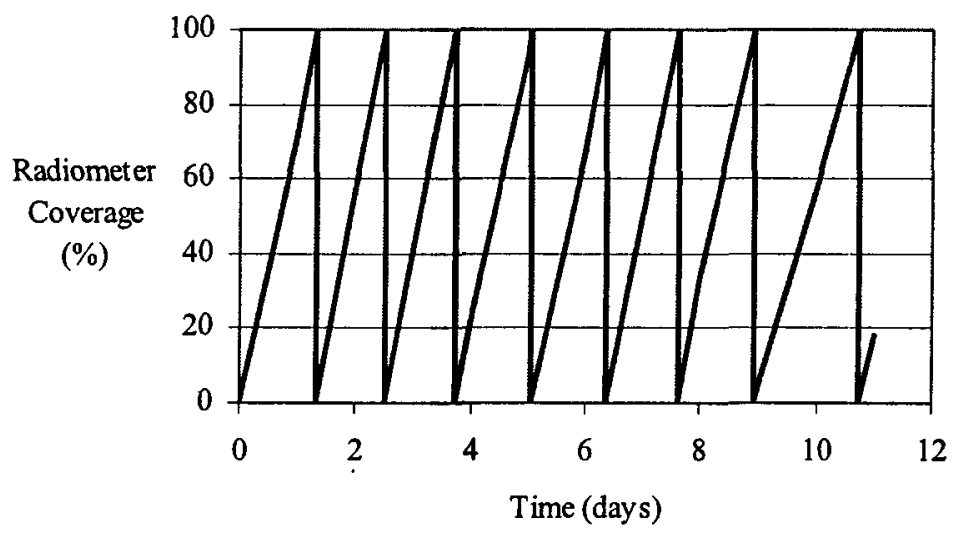

Figure 1. Simulation of the coverage with a decaying orbital altitude

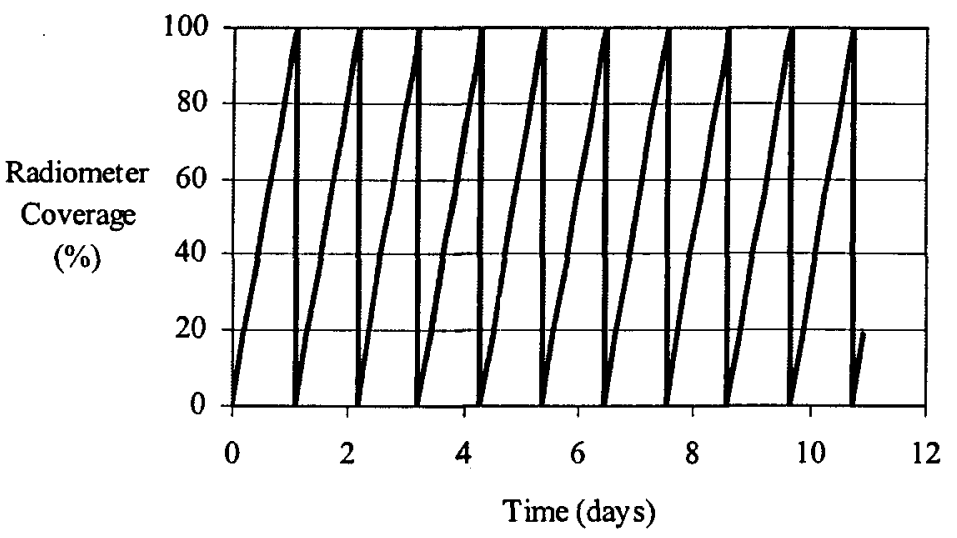

Figure 2. Simulation of the coverage with a constant orbital altitude 


\section{Drag Model}

A model of the drag that the GPM core satellite will encounter was constructed based on the $+2 \sigma$ predictions of the $10.7 \mathrm{~cm}$ solar flux by Schatten $e t$ al. from July 2002, and historical correlations of the flux to a daily average atmospheric density. ${ }^{2}$ The drag was calculated based on a $400 \mathrm{~km}$ altitude circular orbit, a drag coefficient of 2.2, and a satellite effective area of $8.5 \mathrm{~m}^{2}$. This simulation of the drag was performed with FreeFlyer ${ }^{\circledR}$. Simulations and averages were examined for two baseline missions, one starting in January of 2009 (shown in Figure 3), and one starting in 2010.

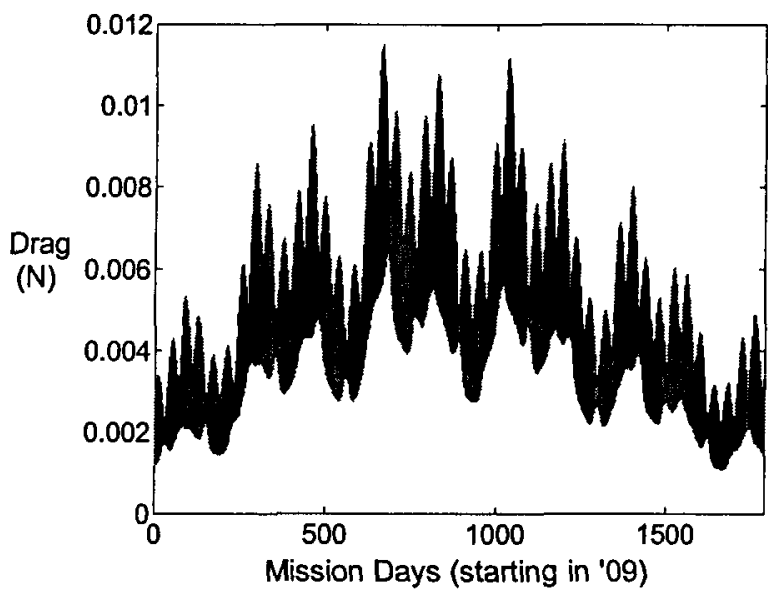

Figure 3. Drag calculations obtained via

FreeFlyer $^{\oplus}$ for a launch in 2009

The two drag histories were numerically integrated to obtain a total impulse for the drag, $I_{\text {total }}$, as shown in Equation 1. The impulse required of the propulsion system will be equal to the total drag impulse if the propulsion system is throttled to maintain a constant orbital altitude.

$$
\mathrm{I}_{\text {total }}=\int \mathrm{Drag} \cdot \mathrm{dt}
$$

The drag compensation impulse was found to be 656,700 Ns for a launch in 2009. The maximum and minimum drag forces were $11.5 \mathrm{mN}$ and 1.1 $\mathrm{mN}$, respectively. The total impulse for a launch in 2010 was considerably lower, around $599,700 \mathrm{Ns}$, with similar maximum and minimum drag levels, due to a decrease in the solar flux after the peak of the solar cycle.

\section{Technology Selection For Drag Compensation}

There are several chemical and electric propulsion system options to maintain a $400 \mathrm{~km}$ altitude. "Propellantless" propulsion devices, such as tethers, also present an interesting alternative. A diagram of these options is shown in Figure 4. Because of the comparatively low specific impulse, all of the chemical propulsion options require significant amounts of propellant for such a large impulse. Maintaining a $400 \pm 5 \mathrm{~km}$ orbit with a chemical propulsion system would require periodic reboosting (from once every two weeks at the beginning of the mission to once a day in 2011).

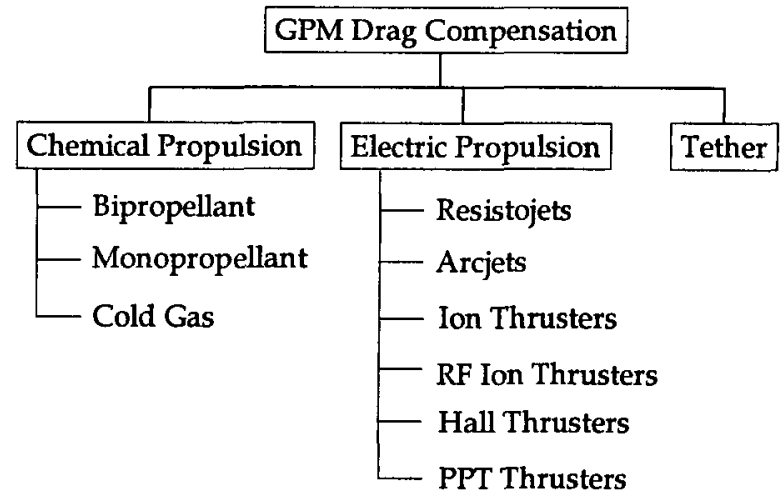

Figure 4. Technology options for drag compensation

Electric propulsion engines generally have much higher specific impulses than chemical thrusters and therefore require less propellant to provide the same total impulse. However, the thrust levels and efficiencies of the EP engines vary considerably between types. For example, no arcjets or resistojets thrusters are available in the thrust range of 1 to $12 \mathrm{mN}$ required for drag compensation.

The inverse is true of the pulsed-plasma thruster (PPT). The thrust levels are far too low, on the order of tenths of milliNewtons. The Hall effect thruster could theoretically produce thrust in the 
required range. However, none of the Hall effect thrusters that are currently available are optimized to operate over the required range. There are several $200 \mathrm{~W}$ systems that could be extended to lower thrust levels, but this could severely limit the lifetime of the engines. ${ }^{3,4}$

Of the remaining principal electrostatic technologies, ion engines and $R F$ ion engines are capable of producing thrust in the required range with little effect on the lifetimes. Although gridded ion engines require more power to produce the same thrust as a Hall engine, they are not lifetime-limited at small thrust levels. The gridded ion engines also have nearly twice the specific impulse of a Hall engine at low power. ${ }^{5}$

\section{EP System Selection}

Although maintaining a constant altitude provides clear scientific benefits, EP drag compensation has additional requirements. Power cycling and orbital considerations (non-constant thrusting produces an elliptical orbit) require that drag compensation be done continuously. This requires that the EP systems be capable of throttling over the entire drag range of 1 to $12 \mathrm{mN}$.

A survey of available electric propulsion systems showed that many systems do not meet the minimum thrust levels. This is in part because many sources do not quote low performance characteristics. Of the systems in the database, there are several that have published information on their low thrust performance, including the UK$10 / \mathrm{T}^{6}$, the NASA GRC $8 \mathrm{~cm}$ ion thruster ${ }^{7}$, the RMT thruster $^{8}$ and the RIT-10 EVO thruster ${ }^{9}$. All four are low-mass, low-power ion engines using xenon propellant, but only the UK-10/T5 has flight heritage (on the ESA's Artemis satellite) ${ }^{6}$ The range of operational specific impulse, thrust and input power on the four thrusters are shown in Table 1, along with data on the mass of the thruster and the Power Processing Unit (PPU), as well as the demonstrated impulse, and Technology Readiness Level (TRL).

The $8 \mathrm{~cm}$ ion engine does not currently cover the entire thrust range, but further development at Glenn Research Center is planned to extend the thrust range. The GPM project requirement for flight technology is that it be brought to TRL 6 (the performance of a model or prototype must be demonstrated in a simulated space environment) before the preliminary design review in 2004 .

\section{EP System Sizing}

The power system was considered separately from the propulsion system. A schematic of the two systems is given in Figure 5 .

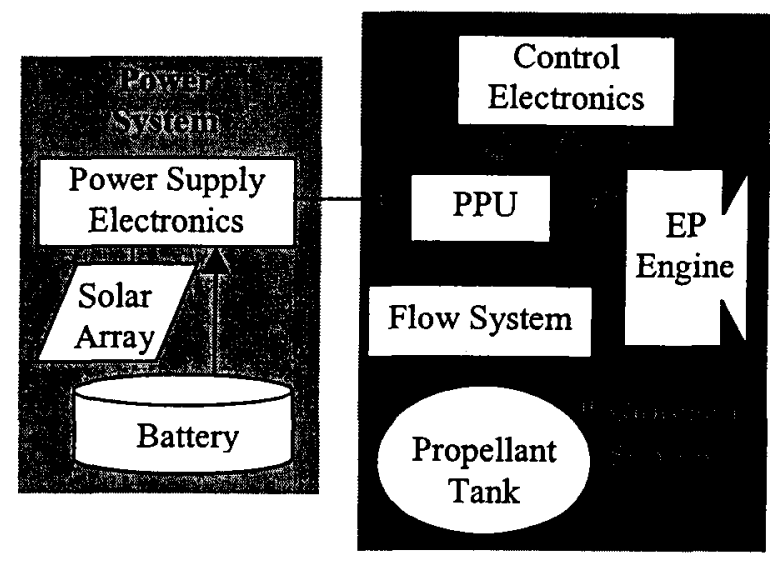

Figure 5. System components schematic

Table 1. Thrusters capable of the entire thrust range

\begin{tabular}{|c|c|c|c|c|c|c|c|c|c|c|}
\hline Device Name & \multicolumn{2}{|c|}{ Impulse } & \multicolumn{2}{|c|}{ Thrust } & \multicolumn{2}{|c|}{ Power to PPU } & Thruster Mass & PPUMass & Demonstrated Impulse & TRL \\
\hline- & Low(s) & High (s) & Low $(\mathbf{N})$ & High (N) & Low $(\mathrm{kW})$ & High $(\mathrm{kW})$ & $\mathrm{kg}$ & $\mathrm{kg}$ & $\mathrm{Ns}$ & $\#$ \\
\hline UK-10T5 & 3090 & 3486 & 0.0005 & 0.035 & 0.275 & 1.75 & 1.7 & 12 & $1,400,000$ & 8 \\
\hline NASA $8 \mathrm{~cm}$ & 1760 & 2650 & 0.0036 & 0.0109 & 0.1 & 0.3 & 0.05 & 5 & 0 & 3 \\
\hline $\mathrm{RMT}$ & 2200 & 3600 & 0.001 & 0.012 & 0.06 & 0.48 & 1.6 & 8.4 & 0 & 4 \\
\hline RT 10EVO & 3000 & 3200 & 0.001 & 0.035 & 0.1 & 1.05 & 1 & 12 & 0 & 6 \\
\hline
\end{tabular}


For each propulsion system in the database, the solar cell array area needed to provide the EOL power required to produce $12 \mathrm{mN}$ of thrust was calculated. A multiple junction GaAs solar cell array was assumed, with a performance degradation rate of $0.5 \%$ per year. The two power configurations considered were an articulated array and a fixed array. For the articulated array, the added solar array area required to power the EP system was fed directly back into the drag model to calculate the drag history. The calculation of solar array area accounts for the effects of solar array pointing and eclipse time (an average of 35 minutes per 93 minute orbit).

In both solar array configurations, the drag history was used to compute the total impulse for the five year mission. The total impulse was used to calculate a propellant requirement for the selected propulsion system (Equation 2). The mass of the EP propulsion systems for the articulated and nonarticulated cases and launches in 2009 and 2010 are shown in Tables 2, 3, 4, and 5 .

$$
\mathrm{m}_{\text {propellant }}=\frac{\mathrm{I}_{\text {total }}}{\mathrm{Isp}(\text { average }) \cdot \mathrm{g}}
$$

Once the additional array dimensions were calculated, the total mass and cost changes to the power system were also computed. ${ }^{10}$ The results shown in Table 6 were calculated for both the articulated and fixed arrays.

This mass could be reduced by tailoring the power supply electronics to the power levels specific to the mission. The power supply electronics (PSEs) used in this study were sized for integral increments of the $750 \mathrm{~W}$ load of the baseline mission design. For the low power NASA $8 \mathrm{~cm}$ ion thruster system with an articulated array, a PSE unit supplies over $500 \mathrm{~W}$ of excess power and has a mass of $60 \mathrm{~kg}$, nearly $3 / 4$ of the total power system mass. The power system designs also considered a nickel-cadmium battery, the baseline battery technology for the mission.

There are additional considerations to be made beyond the mass and power budgets. One of these considerations is the drag induced by the solar arrays. The required maximum thrust levels are significantly higher when an articulated array is used ( $26 \mathrm{mN}$ maximum for the UK-10/T5 thruster, $22 \mathrm{mN}$ for the NASA $8 \mathrm{~cm}$ ion thruster, $24 \mathrm{mN}$ for the RMT thruster, and $23 \mathrm{mN}$ for the RIT 10 EVO thruster) because the cross sectional area of the spacecraft is increased. The maximum drag is only encountered for short durations during solar maximum when the solar array is perpendicular to the ram direction. These brief deviations from the circular orbit can easily be compensated for during the remainder of the orbit.

\section{Mass Comparison}

Based on these estimates for the power system, the mass of the power system would clearly be decreased by using an articulated array. Although the propulsion mass is slightly lower for a fixed array, the lower mass of an articulated array dominates the total mass, as shown in Figure 6.

Figures 6 (a) through (d) show the mass of the EP systems for drag compensation with the four different power configurations and the four EP thrusters. The RMT requires the least propulsion system mass for all power configurations, but also has the second highest total mass. The total mass is dominated by the mass of the power system. The NASA $8 \mathrm{~cm}$ ion thruster requires the least total mass, because the mass of the power system is significantly less. The articulated solar array configuration requires much less total mass, as shown in Figure 6(d). Although the propellant mass required for the articulated array is much higher than for a fixed array, the decrease in the power system mass drives the total mass to be less for the articulated array configurations.

The propellant required for a typical monopropellant system was also considered as a comparison. The initial orbit transfer requires 99 $\mathrm{kg}$ of fuel and approximately $90 \mathrm{~kg}$ of dry mass. The propellant required for drag compensation is $310 \mathrm{~kg}$ assuming an Isp of 230 seconds, with 30 $\mathrm{kg}$ of additional dry mass to store the additional propellant. The total mass of each of the four EP systems is lower than the mass of a chemical system, as illustrated by Figure 7 . 
Table 2. Propulsion system details for a launch in 2009 with a fixed array.

\begin{tabular}{|c|c|c|c|c|c|}
\hline Device Name & Propellant Mass & Propellant Volume & Tank Diameter & Tank Mass & Total Mass \\
\hline- & $\mathrm{kg}$ & $\mathrm{m}^{3}$ & $\mathrm{~m}$ & $\mathrm{~kg}$ & $\mathrm{~kg}$ \\
\hline UK-10/T5 & 19.22 & 0.0136 & 0.3057 & 5.14 & 55.16 \\
\hline NASA $8 \mathrm{~cm}$ & 25.29 & 0.0179 & 0.3350 & 6.17 & 61.46 \\
\hline RMT & 18.61 & 0.0132 & 0.3025 & 5.03 & 46.84 \\
\hline RT 10 EVO & 20.94 & 0.0148 & 0.3146 & 5.44 & 54.38 \\
\hline
\end{tabular}

Table 3. Propulsion system details for a launch in 2010 with a fixed array.

\begin{tabular}{|c|c|c|c|c|c|}
\hline Device Name & Propellant Mass & Propellant Volume & Tank Diameter & Tank Mass & Total Mass \\
\hline- & $\mathrm{kg}$ & $\mathrm{m}^{3}$ & $\mathrm{~m}$ & $\mathrm{~kg}$ & $\mathbf{k g}$ \\
\hline UK-10/T5 & 17.55 & 0.0124 & 0.2966 & 4.84 & 53.19 \\
\hline NASA 8 cm & 23.09 & 0.0163 & 0.3250 & 5.81 & 58.90 \\
\hline RMT & 17.00 & 0.0120 & 0.2934 & 4.73 & 44.93 \\
\hline RIT 10 EVO & 19.12 & 0.0135 & 0.3052 & 5.12 & 52.24 \\
\hline
\end{tabular}

Table 4. Propulsion system details for a launch in 2009 with an articulated array.

\begin{tabular}{|c|c|c|c|c|c|}
\hline Device Name & Propellant Mass & Propellant Volume & Tank Diameter & Tank Mass & Total Mass \\
\hline- & $\mathrm{kg}$ & $\mathrm{m}^{3}$ & $\mathrm{~m}$ & $\mathrm{~kg}$ & $\mathrm{~kg}$ \\
\hline UK-10/T5 & 28.47 & 0.0201 & 0.3485 & 6.68 & 65.95 \\
\hline NASA 8 cm & 31.37 & 0.0222 & 0.3599 & 7.12 & 68.49 \\
\hline RMT & 25.78 & 0.0182 & 0.3371 & 6.25 & 55.23 \\
\hline RIT 10 EVO & 26.99 & 0.0191 & 0.3423 & 6.44 & 61.43 \\
\hline
\end{tabular}

Table 5. Propulsion system details for a launch in 2010 with an articulated array.

\begin{tabular}{|c|c|c|c|c|c|}
\hline Device Name & Propellant Mass & Propellant Volume & Tank Diameter & Tank Mass & Total Mass \\
\hline- & $\mathrm{kg}$ & $\mathrm{m}^{3}$ & $\mathrm{~m}$ & $\mathrm{~kg}$ & $\mathrm{~kg}$ \\
\hline UK-10/T5 & 26.00 & 0.0184 & 0.3381 & 6.28 & 63.09 \\
\hline NASA 8 cm & 28.65 & 0.0203 & 0.3492 & 6.70 & 65.35 \\
\hline RMT & 23.54 & 0.0167 & 0.3271 & 5.88 & 52.62 \\
\hline RIT 10 EVO & 24.65 & 0.0174 & 0.3321 & 6.06 & 58.71 \\
\hline
\end{tabular}

Table 6. Total power system effects.

\begin{tabular}{|c|c|c|c|}
\hline Configuration & Array Size & Power System Mass & Power System Cost \\
\hline & $\mathrm{m}^{2}$ & $\mathrm{~kg}$ & \$M'02 \\
\hline Articulated Array & & & \\
\hline UK-10/T5 & 28.2 & 513 & 7.7 \\
\hline NASA 8 cm Ion & 24.1 & 439 & 7.4 \\
\hline RMT & 26.6 & 484 & 7.6 \\
\hline RIT10 EVO & 25.0 & 454 & 7.5 \\
\hline Fixed Array & & & \\
\hline UK-10/T5 & 48.0 & & 8.4 \\
\hline NASA 8 cm Ion & 41.0 & 713 & 8.2 \\
\hline RMT & 45.2 & 570 & 8.3 \\
\hline RIT10 EVO & 42.4 & 656 & 8.2 \\
\hline Chemical Propulsion & 34 & 599 & 6.3 \\
\hline
\end{tabular}




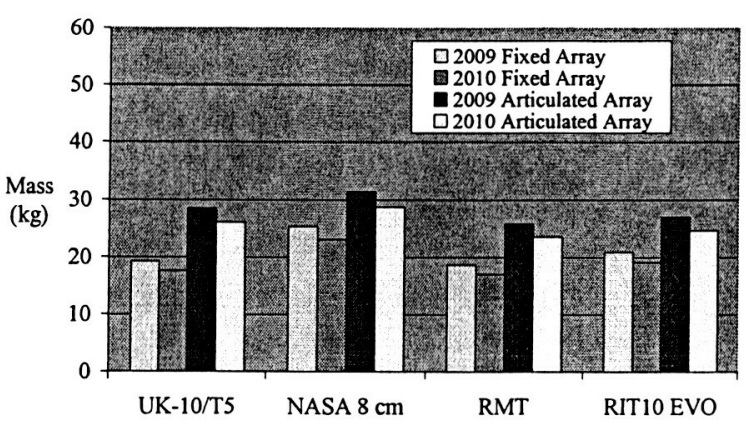

(a) Propellant Mass

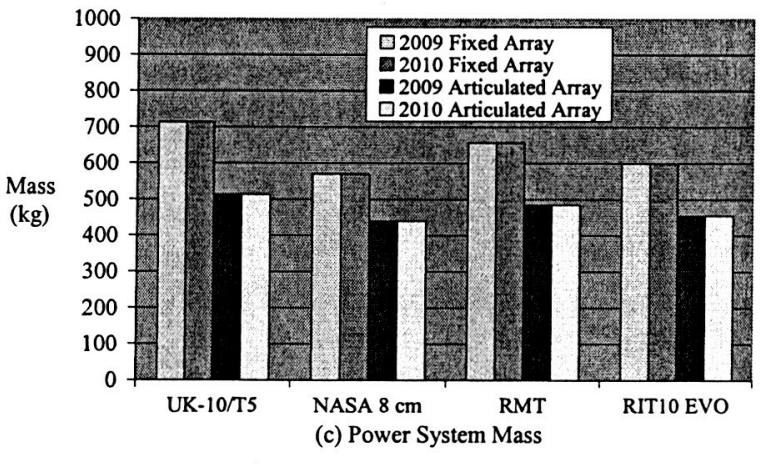

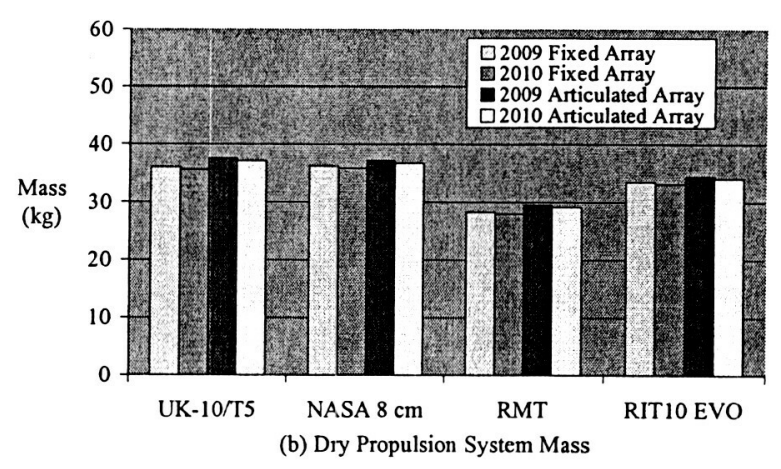

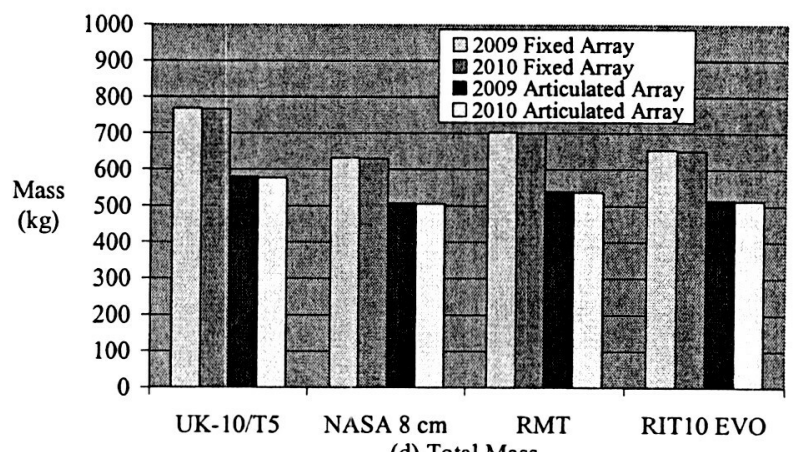

(d) Total Mass

Figure 6. Comparison of the mass of the different configurations.

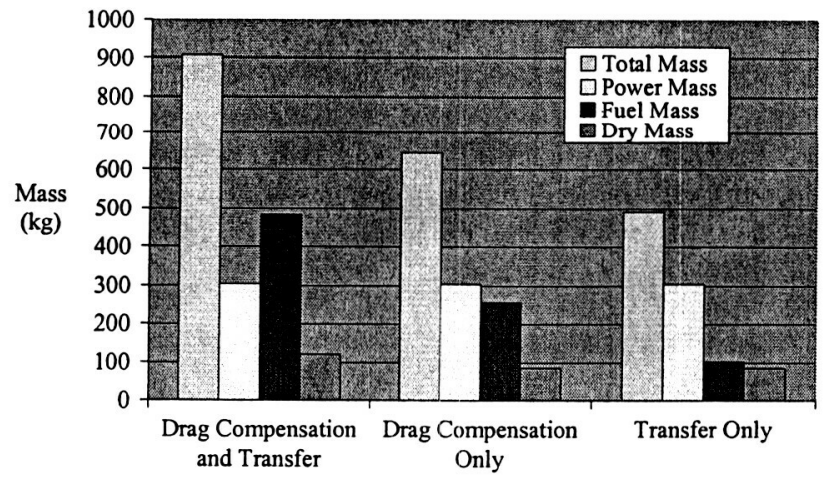

Figure 7. Mass of a chemical propulsion system. 


\section{Propulsion System Cost Estimation}

The costs of the four propulsion systems were obtained via an empirical correlation. ${ }^{11}$ The cost results were broken down into an engineering unit cost, a total flight hardware cost, and development costs. These results are shown in Table 7. The hardware costs include the thrusters, the PPU, the tank, the flow system, and integration and testing. Development costs represent the cost to take the unit from the current status to flight readiness. Further development is already planned for both the NASA $8 \mathrm{~cm}$ ion and RMT thrusters, so it is assumed that this would be funded outside of the GPM mission.

Table 7. Costs of the four possible electric propulsion systems.

\begin{tabular}{|c|c|c|}
\hline Device Name & Engineering Unit Cost & Total Flight Cost \\
\hline- & $\$$ '02 & $\${ }^{\prime} 02$ \\
\hline UK-10/T5 & $2,700,000$ & $6,800,000$ \\
\hline NASA 8 cm & 900,000 & $2,300,000$ \\
\hline RMT & $2,100,000$ & $5,300,000$ \\
\hline RIT 10 EVO & $2,500,000$ & $6,300,000$ \\
\hline
\end{tabular}

\section{$\underline{\text { Cost Comparison }}$}

If the propulsion system costs are considered in conjunction with the costs to modify the power system (presented in Table 6), the total cost is considerably higher. An articulated array with the UK10/T5 system is estimated to cost a total of $\$ 14.5$ million, compared to $\$ 10.9$ million for a chemical system. This cost comparison with both solar array configurations is shown in Figures 8 and 9.

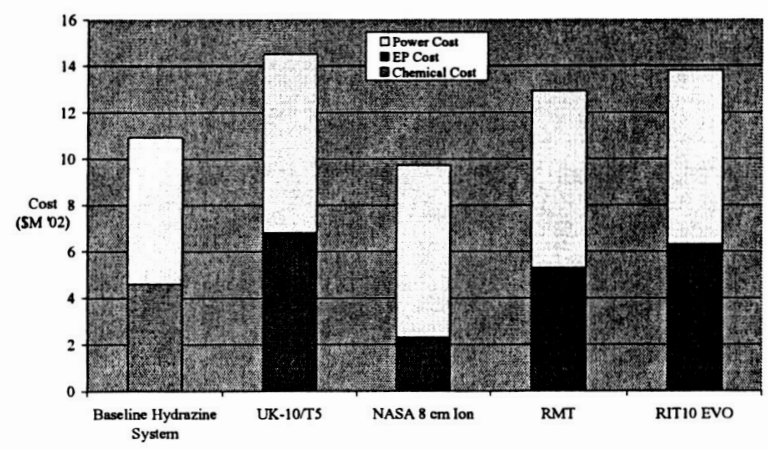

Figure 8. Cost comparison for drag compensation with an articulated solar array.

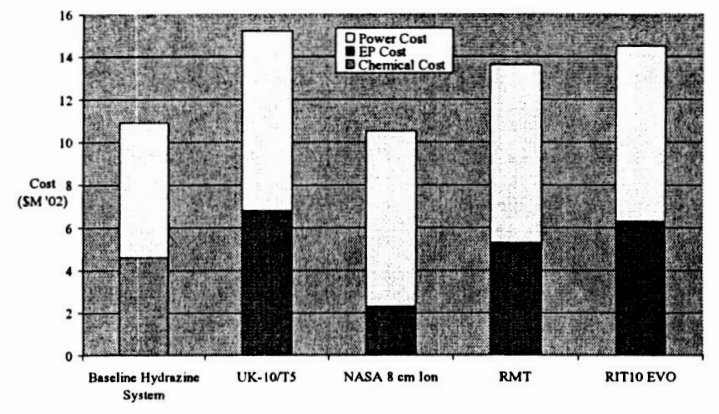

Figure 9. Cost comparison for drag compensation with a fixed solar array.

\section{Orbit Transfer}

The advantage of using the EP system would be greatly improved by eliminating the chemical system and performing the initial orbit transfer with the EP system. The chemical system is currently sized to perform the transfer from the initial $400 \times 650 \mathrm{~km}$ orbit to the $400 \mathrm{~km}$ circular orbit in a few days. Using the EP systems increases the transfer time to approximately 530 days. The propellant requirements for this transfer are given in Table 8 . The transfer requires a total impulse of $190,000 \mathrm{Ns}$.

\begin{tabular}{|c|c|}
\hline & $\begin{array}{c}\text { Propellant } \\
\text { Requirement }(\mathrm{kg})\end{array}$ \\
\hline UK-10/T5 & 6 \\
\hline NASA 8 cm Ion & 9 \\
\hline RMT & 7.5 \\
\hline RIT10 EVO & 6 \\
\hline
\end{tabular}

Table 8. Propellant required for the EP system for orbital transfer.

\section{Dual System Parameters}

Since the transfer times using an EP system are so long, the best technical solution appears to be a "dual" propulsion system with a chemical propulsion system for the orbital transfer and an EP system for the drag compensation. The mass budgets of a dual configuration with either a fixed, 
or an articulated array, are shown in Figures 10 and 11 . The dual system with the NASA $8 \mathrm{~cm}$ ion engine and an articulated array is clearly the best candidate from a mass perspective, with a mass savings of nearly $100 \mathrm{~kg}$ compared to the baseline hydrazine system.

The costs of the dual systems are much higher than the baseline chemical system. The lowest cost dual system with a NASA $8 \mathrm{~cm}$ ion engine requires $\$ 2.9$ million ( $\left.F Y^{\prime} 02\right)$ more than the baseline chemical system. However, there are cost and schedule risks in choosing the $8 \mathrm{~cm}$ ion engine since the engine is not yet fully developed. The dual system with an articulated array and the RIT 10 Evolution thruster provides nearly the same amount of mass savings with much less risk. However, the RIT 10 Evolution-based dual system is even more expensive ( $\$ 7$ million more than the baseline hydrazine system).

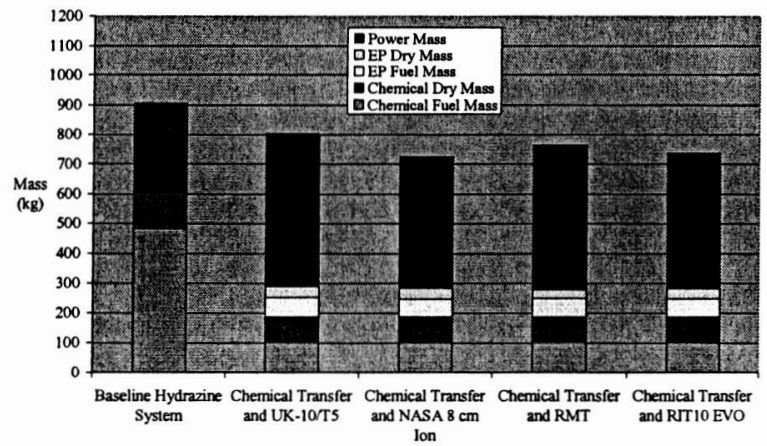

Figure 10. Total mass of a dual propulsion system with an articulated solar array.

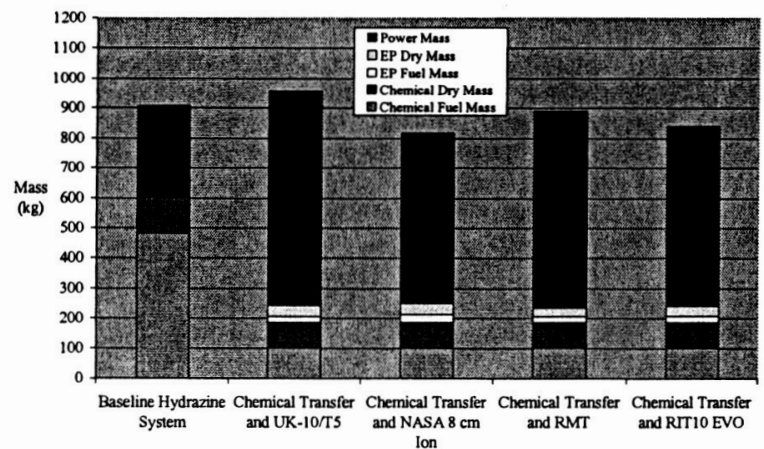

Figure 11. Total mass of a dual propulsion system with a fixed solar array.

\section{Electrodynamic Tether}

Another option for drag compensation is the electrodynamic tether. An electrodynamic tether can be used to produce a low continuous thrust by sending a current through a conducting tether. This current interacts with the magnetic field surrounding the Earth and produces a force on the tether, which can be used to compensate for the atmospheric drag. The thrust produced by the tether is dependant on both the current (and hence the power) and the length of the tether. The length of the tether was sized to compensate for the drag forces induced by the body of the spacecraft, by the tether itself, and by the articulated array required to power the tether. The calculations assumed a $1 \mathrm{~cm}$ diameter aluminum wire. The results of this simulation are shown in Figure 14.

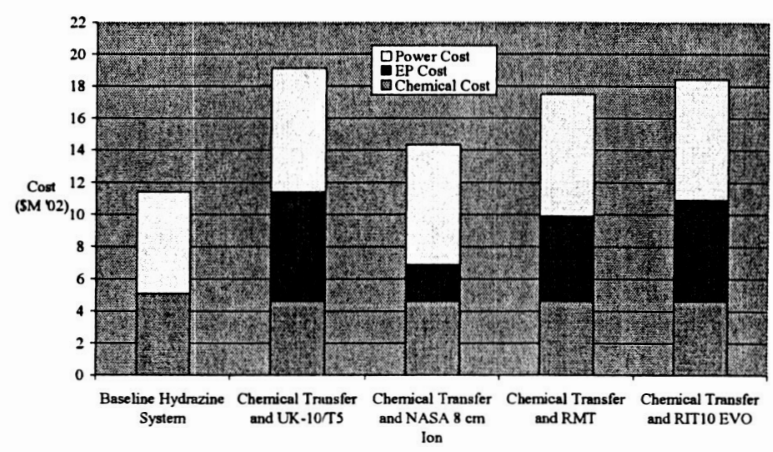

Figure 12. Total cost of a dual propulsion system with an articulated solar array.

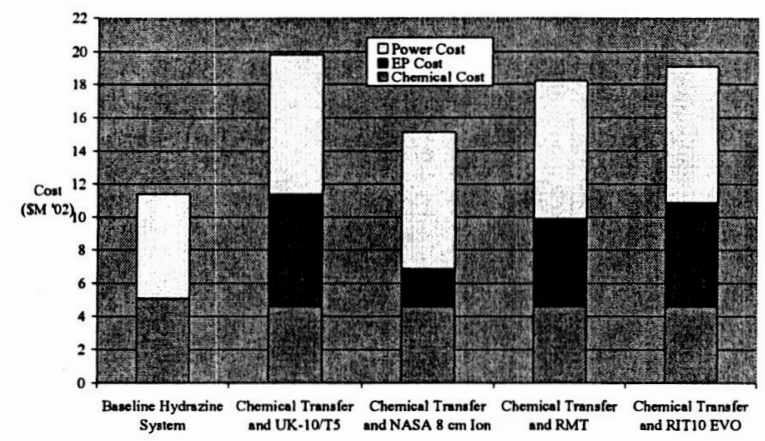

Figure 13. Total cost of a dual propulsion system with a fixed solar array. 


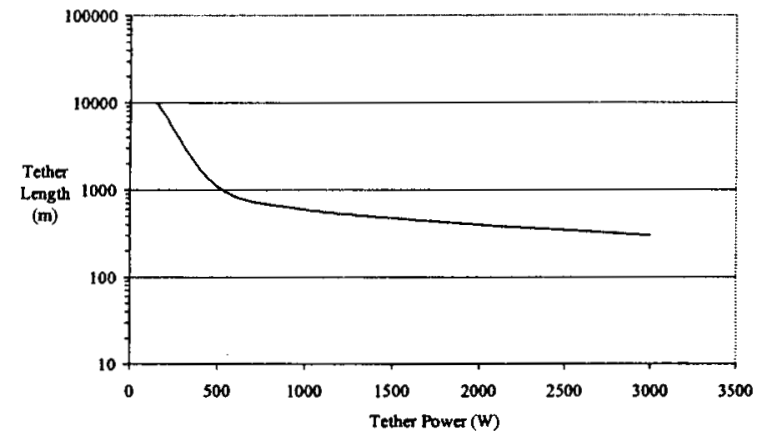

Figure 14. Tether lengths and powers required to compensate for drag in a $400 \mathrm{~km}$ circular orbit.

Feasible combinations of tether lengths and powers could not be attained using the tether system. For short tethers, the power requirements required to drive the tether required very large solar arrays, which added mass. For lower powers, the tether was too long to survive for the five-year mission (the probability of an impact with orbital debris predicts the tether would be severed before the end of the mission).

\section{Conclusion}

Models of the drag environment and the instrument coverage for the Global Precipitation Measurement (GPM) core satellite indicate benefits from using an electric propulsion (EP) system. An electric propulsion system would provide a nearly $20 \%$ increase in the number and rate of global coverages. In addition, the total mass of an EP system is substantially lower than the mass of a chemical propulsion system. However, the costs and orbit transfer times $(\sim 500$ days) of the EP systems are substantially higher than for the baseline hydrazine propulsion system.

The use of a "dual" propulsion system reduces the transfer time, while providing the same benefits of an EP system. The added cost of the "dual" propulsion system is estimated at $\$ 3$ to 8.5 million. Of the four systems selected, the NASA $8 \mathrm{~cm}$ ion engine has the lowest mass for the smallest cost, but with a substantial programmatic risk since it is still under development. It has the potential to save nearly $200 \mathrm{~kg}$ compared to a chemical propulsion system. The RIT10 EVO has the lowest mass and cost while currently meeting the technology readiness requirement, and could save approximately $150 \mathrm{~kg}$ compared to a chemical propulsion system.

A chemical propulsion system was ultimately chosen as the propulsion system for GPM, primarily due to cost. Other studies ${ }^{12}$ have shown that cost savings can be obtained by reducing the mass of spacecraft to either launch more spacecraft, or to move to a smaller launch vehicle. As this case illustrates, when a launch vehicle and the payload are predetermined, the mass savings of electric propulsion for drag compensation do not lead to an overall cost reduction.

However, the trade space is not just limited to the typical mass, power and cost factors. In the case of GPM, improved instrument performance was also a significant factor in the trade study, but cost was the ultimate determining factor.

A different conclusion was reached in the case of the Gravity Field and Steady-State Ocean Circulation Explorer (GOCE) mission by ESA. This mission, which is planned for launch in 2006, requires an electric propulsion system in order to perform the desired scientific measurements. The mission science, precisely measuring the Earth's gravitational field, requires precise compensation for atmospheric drag at low altitude $(250 \mathrm{~km})$ during solar minimum using the UK 10/T5 thruster. ${ }^{13}$

While cost will continue to be a driver for NASA missions, advances in sensor technology will continue to push the requirement for precise orbital altitudes. Electric propulsion will be needed to perform drag compensation for these missions, and will allow substantial mass savings, as illustrated here for GPM.

\section{Acronym List}

EP Electric Propulsion

ESA European Space Agency 
GOCE Gravity field and steady-state Ocean Circulation Explorer

GPM Global Precitpitation Measurement

GRC Glenn Research Center

NASA National Aeronautics and Space Administration

PPU Power Processing Unit

PSE Power Supply Electronics

RIT Radio-Frequency Ion Thruster

\section{References}

1. Mailhe, L., C. Schiff, C. Mendehlsohn, D. Everett, and D. Folta, "Global Precipitation Measurement - Report 9: Core Coverage Trade Space Analysis", NASA/TM-2002-211615, September 2002.

2. Schatten, K., Dr. Schatten Source Files, NASA Goddard Flight Dynamics Facility, http://mmfd.gsfc.nasa.gov/prod_center/pc frame_page.htm, Accessed: 10/5/2002.

3. Hruby, V., J. Monheiser, B. Pote, C. Freeman, and W. Connolly, "Low Power, Hall Thruster Propulsion System", 26 ${ }^{\text {th }}$ International Electric Propulsion Conference, October 17-21, 1999, Kitakyushu, Japan, IEPC-99-092.

4. Hruby, V., personal communication, 10/14/02.

5. Killinger, R., H. Bassner, and J. Mueller, "Development of an High Performance RF-Ion Thruster", $35^{\text {th }}$

AIAA/ASME/SAE/ASEE Joint Propulsion Conference, 20-24 ${ }^{\text {th }}$ June, 1999, Los Angeles, CA, AIAA Paper No. 99-2445.

6. Crofton, M.W., "Evaluation of the United Kingdom Ion Thruster", Journal of Spacecraft and Rockets, Vol. 33, No. 5, September-October 1996, pp. 739-747.
7. Foster, John. E., and Michael J. Patterson, "Internal Plasma Properties and Enhanced Performance of an 8-cm Ion Thruster Discharge", NASA/TM-1999-209386, October 1999.

8. Saccoccia, G., J. Gonzalez del Amo, and D. Estublier, "Electric Propulsion: A key Technology for Space Missions in the New Millenium", ESA Bulletin 101, February 2000.

9. Killinger, R., H. Bassner, J. Müller, "Development of an High Performance RF-Ion Thruster", $35^{\text {th }}$

AIAA/ASME/SAE/ASEE Joint Propulsion Conference, 20-24 June, 1999, AIAA Paper No. 99-2445.

10. Apgar, H., and D. Bearden, "Cost Modeling", Space Mission Analysis and Design, $3^{\text {rd }}$ Edition, edited by J. R. Wertz, and W. J. Larson, pp. 783-820, Copyright 1999, by Microcosm, Inc..

11. Reichbach, J., R. Sedwick, and M. Martinez-Sanchez, "Micropropulsion System Selection for Precision Formation Flying Satellites", January 2001, M.S. Thesis, MIT, SERC\#1-01.

12. Oleson, Steven R., "Electric Propulsion for Low Earth Orbit Communication Satellites", $25^{\text {th }}$ International Electric Propulsion Conference, Cleveland Ohio, August 24-28, 1997, NASA Contractor Report 204152.

13. Johannessen, J. A., "The Four Candidate Earth Explorer Core Missions Gravity Field And Steady-State Ocean Circulation", ESA SP-1233(1), Copyright 1999, European Space Agency. 